\title{
Comparison of two Three-Phase PLL Systems for More Electric Aircraft Converters
}

\author{
Stefano Bifaretti ${ }^{*}$ Member, IEEE, Pericle Zanchetta ${ }^{* *}$, Member, IEEE, Elisabetta Lavopa ${ }^{* *}$ \\ *Dept. of Industrial Engineering - University of Rome Tor Vergata (Italy) - bifaretti@ing.uniroma2.it \\ ** Dept. of Electrical and Electronic Engineering-University of Nottingham (UK)-Pericle.Zanchetta@nottingham.ac.uk
}

\begin{abstract}
The More Electric Aircraft power system is characterized by variable supply frequency, in general between $360 \mathrm{~Hz}$ and $900 \mathrm{~Hz}$. All equipment on board the aircraft have to operate delivering high performance under this variable frequency condition. In particular, power electronic converters need accurate control algorithms able to track the fundamental phase and frequency in real time, both in normal and unusual conditions. Phase Locked Loop (PLL) based algorithms are commonly used in traditional single and three phase power systems to provide phase and frequency estimations of the supply. Despite the simplicity of those algorithms, large estimation errors can arise when power supply voltage has variable frequency or amplitude, presents unbalances or is polluted with harmonics. To improve the quality of the phase and frequency real-time estimations, a robust PLL algorithm, based on a predictioncorrection filter, is presented in this paper and compared with a Discrete Fourier Transform (DFT) based procedure. The performances of the two algorithms, implemented in a floatingpoint DSP, have been compared through an experimental validation obtained on a laboratory power converter prototype.
\end{abstract}

\section{INTRODUCTION}

The More Electric Aircraft follows the technological trend in modern aerospace industry to increasingly use electrical power onboard in place of mechanical, hydraulic and pneumatic power to drive aircraft subsystems such as flight surface actuators, flight control, passenger entertainment, etc. The higher use of electrical power presents significant advantages such as optimization of performance and life cycle cost of the aircraft, reduction of the fuel consumption, reduction of weight and size of the system equipment as well as the potential for improved condition monitoring and maintenance cycles. However, the More Electric Aircraft will bring major changes in the aircraft electrical power system, such as an increase of electrical loads and power electronic equipment, a more complex electrical network, significantly higher levels of electrical distribution which in turn result in greater power quality and stability problems [1]-[3]. In a modern aircraft power network two electrical generators are connected to each engine, providing variable frequency supply through a distribution system based on two AC buses. Two DC buses are also derived from the $\mathrm{AC}$ ones by means of active rectifiers. $\mathrm{AC}$ and DC loads, power electronic converters, energy storage elements and active filters for harmonic compensation are then supplied by the buses [3]. A fast and exact estimation of fundamental line frequency and phase is necessary for all power electronic converters in this system where the variable frequency supply, generally between $360-900 \mathrm{~Hz}$, makes this task quite challenging. A software estimation, achieved using simple voltage measurements, is certainly more convenient with respect to a direct measurement with sensors coupled to generators. Additional sensors, in fact, produce larger costs and an increased mechanical complexity, while reducing as well the system reliability. In the case of an active filter, harmonic content of the current drawn by non-linear loads is also required in order to calculate an accurate reference signal for the control algorithm to achieve precise harmonic compensation.

Several algorithms for harmonic analysis and frequency estimation have been proposed in the literature. The recursive Discrete Fourier Transform [4],[5], the least error square technique [6], [7], the Kalman filter [8]-[10] are some of the most commonly used techniques, along with the wavelet transform, the PQ theory, and the neural networks. Other solutions, characterized by a lesser computational complexity, are based on Phase-Locked Loop (PLL) systems, which have been widely proposed in the literature [11]-[35] in order to obtain a robust synchronization with the supply fundamental voltage. The most common approaches [12]-[19] employ a second-order closed-loop transfer function that presents difficulties in the parameters tuning due to the trade-off between noise rejection (narrow bandwidth) and fast response (high bandwidth). In addition, the PLL may fail to lock to the input signal during the start-up transient, when some adverse conditions occur, if the frequency variation of the controller is not limited [19]. To overcome such problems different approaches, based on adaptive algorithms, have been proposed in literature: in [20] three different control units are employed in order to provide separate estimation of phase angle, frequency and voltage amplitude, while in [21] an adaptive mechanism that can be applied to other PLL structures has been proposed. Such methods provide good transient and steady-state performance, but their structure is quite complex and requires a heavy computational effort. Moreover, under unbalanced grid conditions, the PLL input becomes affected by a negative sequence that can be attenuated only by a strong reduction of the system bandwidth [22]. To reduce the effect of the negative sequence without compromising the system dynamics, different structures have been proposed in the literature based on the extraction of the positive and negative sequences [23]-[25], on the estimation of the grid harmonics [26], on a repetitive controller with a DFT algorithm [27], on harmonics cancellation [28]-[30] and on a dual second-order 
generalized integrator frequency-locked loop [31]. This paper proposes a different PLL solution, based on a third-order linear and time-invariant observation model derived from a SteadyState Linear Kalman Filter (SSLKF). This structure has also been employed to reduce the speed measurement noise in drives using an electromagnetic resolver [32], allowing an accurate tracking of the input signals, even in critical conditions. A practical procedure to easily perform the tuning of filter parameters is presented as well as an approximated transfer function to determine the bandwidth. The choice of a SSLKF allows the reduction of the computational effort, as the correction gain vector can be calculated off-line.

Since the performances of the SSLKF-based PLL has been already proven for standard grid-connected systems in [33][34], in this paper the method is experimentally compared with the phase and frequency estimation technique proposed in [35] which adopts a real-time DFT technique as the PLL phase detector. Such choice for the comparison is justified since the DFT technique has been specifically designed for aircraft power systems providing, as shown in [35], superior performances in case of variable frequency power supplies amongst other conventional PLL solutions. Moreover, it is important to highlight that the most common PLL structures are designed to operate only around a rated frequency that in conventional grid-connected applications is fixed [17],[22],[24], [28] and, thus, cannot be used in case of a variable frequency supply. The experimental tests have been performed in compliance to Aircraft power systems standards DO-160E [36].

This paper is structured as follows. First, the description of traditional PLL techniques and of the SSLKF is given. Then, a brief description of the DFT-based technique chosen for the comparison is also presented. Finally, experimental results obtained from a real-time DSP implementation of both algorithms are illustrated and discussed.

\section{PLL SYSTEM OVERVIEW}

The simplest PLL architecture is based on a closed-loop system formed by a phase detector, a low-pass filter and a voltage-controlled oscillator (VCO) [15], [16]. In such architecture, widely used in hardware implementations, the detection of phase and frequency is based on the zero-crossing points of the input signal. The dynamic performances of such solution are limited because the zero-crossing detection is performed only every half of fundamental cycle [15] and the measurement noise can produce oscillations on the phase angle. Alternative solutions, particularly suitable for threephase systems and software implementation, are based on different phase detectors which uses an error signal obtained by a $d q$ transformation (SRF-PLL) [17],[22],[24],[28] or by a vector product [16],[18],[19].

Fig. 1 shows the block diagram of a PLL system based on the vector product between the grid measured voltage phasor and the phase estimated by the PLL. The signal error $e$ furnished by the vector product is approximated by its sine and it is obtained as:

$$
\begin{aligned}
& e \cong \sin \left(\theta_{m}-\tilde{\theta}\right)=\sin \theta_{m} \cdot \cos \tilde{\theta}-\cos \theta_{m} \cdot \sin \tilde{\theta}= \\
& =\frac{v_{\beta} \cdot \cos \tilde{\theta}-v_{\alpha} \cdot \sin \tilde{\theta}}{V_{S}}
\end{aligned}
$$

where $v_{\alpha}$ and $v_{\beta}$ are the real and imaginary components of the grid voltage phasor, referred to a stationary reference frame $\alpha \beta$, $V_{S}$ and $\theta_{m}$ are the module and the phase of the grid voltage phasor, $\tilde{\theta}$ is the phase angle estimated by the PLL.

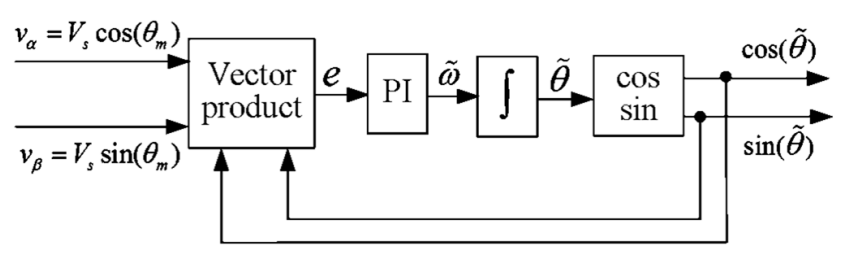

Fig. 1. Block diagram of a PLL system based on the vector product.

A loop filter, usually represented by a Proportional Integral (PI) regulator followed by an integrator, provides the estimated values of the angular frequency $\tilde{\omega}$ and phase $\tilde{\theta}$. Finally, the sine and cosine of the angle $\tilde{\theta}$ are calculated by means of a numerical procedure or a look-up table. In this paper a deterministic prediction-correction filter, derived by a SteadyState Linear Kalman Filter (SSLKF), is used as a loop filter.

\section{PREDiction-CORRECTION FILTER}

The prediction correction filter has been already used for utility-connected applications [33]-[34] in which a secondorder filter is sufficient to assure good performance since the grid frequency does not presents significant variations during normal operating conditions. On the contrary, in aircraft power systems, the power supply frequency varies (aircraft standards DO-160E consider a linear variation), so the angular acceleration is not zero during normal operating conditions. In order to obtain a negligible tracking error during a supply frequency ramp, the third-order dynamic model of the SteadyState Linear Kalman Filter [33] has to be employed.

\section{A. Mathematical Model}

In this paper a deterministic filter structure is considered, composed as a prediction model followed by a correction model, both expressed in a discrete-time form, since the PLL system has to be implemented in digital devices. The thirdorder physical prediction model, based on the electrical grid equations, can be written as follows:

$$
\begin{aligned}
& \boldsymbol{x}_{n}=\boldsymbol{A} \boldsymbol{x}_{n-1} \\
& y_{n}=\boldsymbol{c}^{T} \boldsymbol{x}_{n}
\end{aligned}
$$


where:

$$
\begin{aligned}
& \boldsymbol{x}=\left[\begin{array}{l}
\theta \\
\omega \\
a
\end{array}\right] \quad \boldsymbol{A}=\left[\begin{array}{ccc}
1 & T & T^{2} / 2 \\
0 & 1 & T \\
0 & 0 & 1
\end{array}\right] \\
& \boldsymbol{c}^{T}=\left[\begin{array}{lll}
1 & 0 & 0
\end{array}\right],
\end{aligned}
$$

$n$ is the sampling instant index,

$T$ is the sampling interval,

$\theta$ is the grid voltage phase angle,

$\omega$ is the grid angular frequency,

$a$ is the derivative of the grid angular frequency,

$y$ is the computed value of the phase angle.

On the basis of dynamic model (2), prediction-correction filter performs the following two steps:

1) prediction of the state at the subsequent sampling instant:

$$
\tilde{\boldsymbol{x}}_{n}=\boldsymbol{A} \hat{\boldsymbol{x}}_{n-1}
$$

2) correction of predicted state on the basis of the prediction phase error $e_{n}=\theta_{n}-c^{T} \tilde{\boldsymbol{x}}_{n}$ :

$$
\hat{\boldsymbol{x}}_{n}=\tilde{\boldsymbol{x}}_{n}+\boldsymbol{g} e_{n} \text {. }
$$

Coefficients $g_{1}, g_{2}$ and $g_{3}$ of the correction vector $\boldsymbol{g}=\left[\begin{array}{lll}g_{1} & g_{2} & g_{3}\end{array}\right]^{T}$ can be selected by imposing the position of the filter poles.

\section{B. Design Procedure}

Combining the prediction equation (3) at sampling instant $n$ with the correction equation (4), at the previous sampling instant:

$$
\hat{\boldsymbol{x}}_{n-1}=\tilde{\boldsymbol{x}}_{n-1}+\boldsymbol{g}\left(\theta_{n-1}-\boldsymbol{c}^{T} \tilde{\boldsymbol{x}}_{n-1}\right),
$$

the following dynamic equation of the prediction-correction filter is obtained:

$$
\tilde{\boldsymbol{x}}_{n}=\hat{\boldsymbol{A}} \tilde{\boldsymbol{x}}_{n-1}+\boldsymbol{A g} \theta_{n-1}
$$

being $\hat{\boldsymbol{A}}=\boldsymbol{A}\left(\mathbf{I}-\boldsymbol{g} \boldsymbol{c}^{\mathrm{T}}\right)$.

The prediction-correction filter poles can be imposed, on the basis of the desired bandwidth, by equating the eigenvalues of the characteristic equation associated to dynamic matrix $\hat{\boldsymbol{A}}$ to those of a third-order discrete filter.

Transforming in $z$-domain the discrete-time eq. (5) and choosing, as input, the measured grid angle $\theta$, the following equations can be obtained:

$$
\left\{\begin{array}{l}
\tilde{\theta}=G_{1}(z) \cdot \theta \\
\tilde{\omega}=G_{2}(z) \cdot \omega \\
\tilde{a}=G_{3}(z) \cdot a
\end{array}\right.
$$

in which the transfer functions $G_{l}(z), G_{2}(z)$ and $G_{3}(z)$ are expressed as:

$$
\begin{aligned}
& G_{1}(z)=\frac{\left(g_{3} T^{2} / 2+g_{2} T+g_{1}\right) z^{2}+\left(g_{3} T^{2} / 2-2 g_{2} T-2 g_{1}\right) z+g_{1}}{z^{3}+c_{2} z^{2}+c_{1} z+c_{0}} \\
& G_{2}(z)=\frac{\left(g_{3} T+g_{2}\right) z-g_{2}}{z^{3}+c_{2} z^{2}+c_{1} z+c_{0}} T \\
& G_{3}(z)=\frac{T^{2} g_{3}}{z^{3}+c_{2} z^{2}+c_{1} z+c_{0}} \\
& \text { being } \\
& c_{0}=g_{1}-1 \\
& c_{1}=\left(g_{3} T^{2} / 2-g_{2} T-2 g_{1}+3\right) \\
& c_{2}=\left(g_{3} T^{2} / 2+g_{2} T+g_{1}-3\right)
\end{aligned}
$$

The poles of the $z$-transfer functions can be calculated by the discretization of a continuous filter. Choosing a third-order filter characterized by a negative real pole $s_{0}$ and a complex poles pair $s_{1,2}$ :

$$
s_{0}=-\omega_{n} R, \quad s_{1,2}=-\omega_{n} \operatorname{Exp}( \pm j \phi)
$$

being $\mathrm{R}>0$ and $0^{\circ}<\phi<90^{\circ}$, the $z$-transfer functions poles becomes:

$$
\begin{aligned}
& \rho_{0}=\operatorname{Exp}\left(-\omega_{n} R T\right), \\
& \rho_{1}=\operatorname{Exp}\left(-\omega_{n} T \cos (\varphi)\right), \quad \varphi=\omega_{n} T \sin (\phi) .
\end{aligned}
$$

As a consequence, the denominator coefficients of the $z$ transfer functions can be written as:

$$
\begin{aligned}
& c_{2}=-2 \rho_{1} \cos (\varphi)-\rho_{0}, \\
& c_{1}=\rho_{1}\left[2 \rho_{0} \cos (\varphi)+\rho_{1}\right], \\
& c_{0}=-\rho_{0} \rho_{1}^{2} .
\end{aligned}
$$

Finally, from (6) and (8), the elements of the vector $\boldsymbol{g}$ can be calculated as:

$$
\begin{aligned}
& g_{3}=\frac{c_{1}+c_{0}+c_{2}+1}{T^{2}}, \\
& g_{2}=\frac{c_{1}-c_{0}+3 c_{2}+5}{2 T}-T g_{3}, \\
& g_{1}=c_{2}+3-T g_{2}-g_{3} T^{2} / 2 .
\end{aligned}
$$

The design parameters $\omega_{\mathrm{n}}, R$ and $\phi$ are used to set the desired bandwidth and transient response. The filter bandwidth depends mainly on $\omega_{\mathrm{n}}$, but it is affected secondarily also by $R$ and $\phi$. Its choice, as it is well-known, is a compromise between the tracking speed of the system and the capability to reject disturbances. In order to observe how the bandwidth depends on $R$ and $\phi$ and simplify the parameters selection, it is convenient to calculate an approximated $s$-transfer function 
from which is possible to evaluate how the design parameters affect the performance of the filter. To this aim, the zero $z_{2}$ of transfer function $G_{2}(z)$ between the estimated and grid frequency

$$
z_{2}=\frac{g_{2}}{g_{3} T+g_{2}}
$$

is mapped in $s$-domain as:

$$
z_{2 s}=-\omega_{n} T \ln \left(\frac{g_{3}}{g_{2}} \mathrm{~T}\right)
$$

Using a first order Taylor expression and a suitable approximation the following expression can be obtained:

$$
z_{2 s} \simeq-\frac{R \omega_{n}}{1+2 R \cos \phi}
$$

Thus, the following approximated $s$-transfer function is achieved:

$$
G_{2}(s)=\frac{(1+2 R \cos \phi) \omega_{n}^{2} s+R \omega_{n}^{3}}{s^{3}+(R+2 \cos \phi) \omega_{n} s^{2}+(1+2 R \cos \phi) \omega_{n}^{2} s+R \omega_{n}^{3}}
$$

Fig. 2a illustrates the frequency response of the proposed filter, normalized at $\omega_{n}=1$, for different values of $R$ with a fixed angle $\phi$, equal to $45^{\circ}$. As it can be noticed, the Normalized Bandwidth $(\mathrm{NBw})$, calculated at $-3 \mathrm{~dB}$, becomes wider as $\mathrm{R}$ increases whilst the peak amplitude lightly decreases as well as the slope of the first descending interval. This effect is due to the mutual position of the pole $s_{0}$ and the zero $z_{2 s}$. In fact, for $\mathrm{R}<1, s_{0}$ becomes lower than $\omega_{n}$ while it moves at higher frequencies for $\mathrm{R}>1$. On the contrary, $z_{2 s}$ remains lower than $\omega_{n}$ for any value of $\mathrm{R}$. This implies that increasing the value of $\mathrm{R}$, a step response for $\omega$ will be characterized by lower overshoot, higher speed but lesser filtering capability. From Fig. 2b, which shows the normalized frequency response for different values of $\phi$ with $R=1$, it can be highlighted that angle $\phi$ mainly affects the peak amplitude, while $\mathrm{NBw}$ remains almost constant. In Table I the NBw values, obtained for significant values of $R$ and $\phi$, are reported.

As a conclusion, the design procedure can be summarized in the following steps:

1. chose the desired bandwidth $\omega_{d}$;

2. chose $R$ and $\phi$ on the basis of desired frequency response and determine $\mathrm{NBw}$;

3. calculate $\omega_{n}=\omega_{d} / \mathrm{NBw}$;

4. use (7), (8) and (9) to compute the gain values $g_{1}, g_{2}$ and $g_{3}$ employed in prediction equation (4).

Table I. Normalized bandwidth for different R and $\phi$ values.

\begin{tabular}{|c|c|c|c|c|}
\hline & \multicolumn{4}{|c|}{ Normalized Bandwidth (NBw) } \\
\hline$R$ & $\phi=15^{\circ}$ & $\phi=30^{\circ}$ & $\phi=45^{\circ}$ & $\phi=60^{\circ}$ \\
\hline 0.5 & 1.31 & 1.37 & 1.45 & 1.54 \\
\hline 1 & 1.65 & 1.67 & 1.69 & 1.70 \\
\hline 2 & 2.02 & 1.99 & 1.94 & 1.85 \\
\hline 5 & 2.40 & 2.30 & 2.13 & 1.92 \\
\hline 10 & 2.48 & 2.35 & 2.14 & 1.89 \\
\hline
\end{tabular}

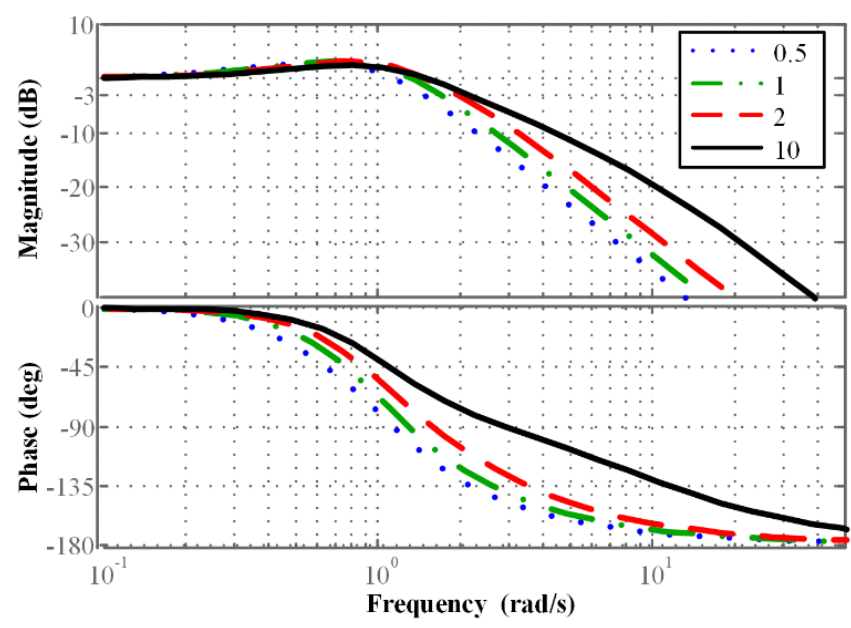

(a)

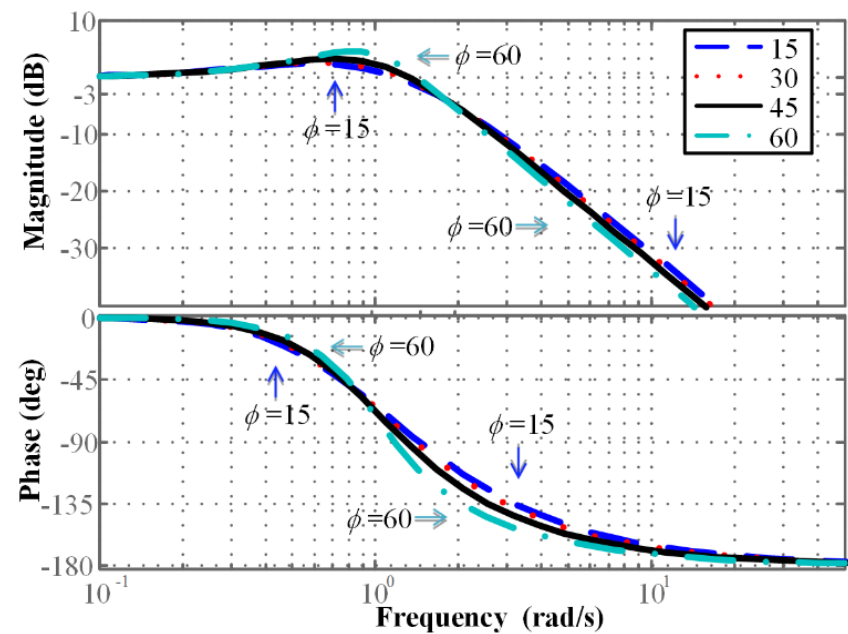

(b)

Fig. 2. Frequency response of prediction-correction filter: (a) for different values of $\mathrm{R}$ and $\phi=45^{\circ}$ (b) for different values of $\phi$ and $\mathrm{R}=1$.

\section{THE DFT-BASED PLL TECHNIQUE}

In order to validate the technique presented in the previous sections, a comparison with a different algorithm for phase and frequency detection proposed in [35] has been performed.

Fig. 3 shows the block scheme of this technique and its correspondence with the structure of a classic PLL. In such approach, the phase detector is an algorithm based on the Discrete Fourier Transform, as shown in Fig. 4.

The DFT-PLL algorithm is based on the principle that in the frequency domain the fundamental component of a signal has the highest amplitude. When the exact value of fundamental frequency is unknown it can be detected, within the limits of the frequency resolution, by finding the highest component in the voltage (or current) spectrum and calculating its corresponding frequency.

Assuming that the value of frequency is approximately known, which is often the case in an electrical power system, an initial value $f_{l}$ is chosen as an estimate. Given the initial guess $f_{l}$, it is possible to obtain an estimate $\Delta f$ of the difference 
between $f_{1}$ and the actual value of the fundamental frequency. The estimated $\Delta f$ depends on the amplitudes of three spectral components: the one at $f_{l}$ and the two adjacent ones at $f_{l} \pm d f$, where $d f$ is the frequency resolution of the DFT. $\Delta f$ is calculated according to (10):

$$
\Delta f=\frac{1.5 \cdot d f \cdot a m_{1} \cdot\left(a m_{11}-a m_{12}\right)}{\left(a m_{1}+a m_{11}\right) \cdot\left(a m_{1}+a m_{12}\right)}
$$

where $a m_{1}$ is the amplitude of the spectral line at frequency $f_{l}$, $a m_{11}$ and $a m_{12}$ are the amplitudes of the right and the left components at $f_{l}+d f$ and $f_{l}-d f$ respectively [35]. The error between $\Delta f$ and its actual value decreases to zero with $\Delta f$ itself. The value $\Delta f$ is then used as error signal for the PI loop filter that gives the estimated value of the fundamental frequency. The estimated frequency is then multiplied by $2 \pi$ and integrated to obtain the estimated phase of the fundamental signal and this is used to calculate the three amplitudes $a m_{1}$, $a m_{11}$ and $a m_{12}$ using the DFT algorithm.

The distorted three-phase voltage (or current) signals can be mathematically expressed as the sum of many complex exponential functions representing the harmonic components. These exponential functions correspond to vectors rotating at speed $\pm m \omega_{1}$ (+ for positive sequence harmonics and - for negative sequence), where $m$ is the harmonic order and $\omega_{l}$ $=2 \pi f_{l}$ is the fundamental. In order to extract the $m^{\text {th }}$ harmonic component from the signal, this is represented in a reference frame rotating at the same harmonic angular frequency, where the harmonic appears as a DC quantity. Therefore its mean value can be calculated, providing information about amplitude and phase of the spectral component. This operation is performed on the three reference frames rotating at the three speeds $\omega_{1}, \omega_{1}+d \omega, \omega_{1}-d \omega$, where $\omega_{1}$ is the estimate of fundamental and $d \omega=2 \pi d f$ is the spectral resolution in radians per second. The DFT-PLL can be implemented in real time and applied to a vector that contains the last $n$ samples of the signal.

Fig. 4 represents the block diagram utilized for the calculation of the amplitude and the phase of the fundamental spectral component. The same scheme is adopted for the calculation of the amplitudes $a m_{11}$ and $a m_{12}$.

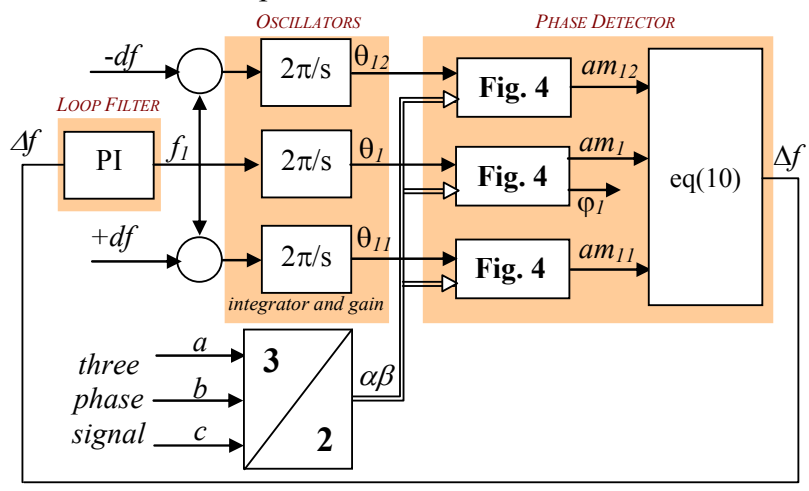

Fig. 3. Scheme of the DFT-PLL algorithm.

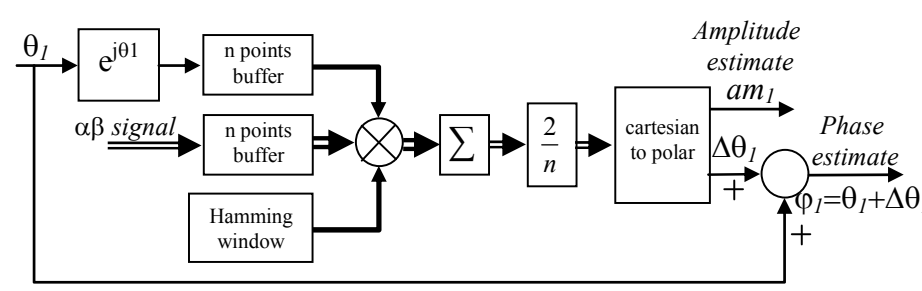

Fig. 4. Block diagram adopted for the calculation of the DFT component am and phase $\varphi_{1}$

\section{EXPERIMENTAL RESULTS AND COMPARISON}

The SSLKF-PLL algorithm, as well as the DFT-PLL, has been tested on an experimental rig with the structure shown in Fig. 5. The experimental rig comprises a 10kVA three-phase shunt active filter (ASF) controlled by a Texas Instruments TMS320C6713 32-bit floating point DSP running at $250 \mathrm{MHz}$. Data acquisition and pulse generation are coordinated by an Actel Proasic A500K050 FPGA. A three-phase programmable power source, Chroma 61705, supplies voltage to the rig. A non-linear load represented by an inductively smoothed diode bridge rectifier is connected in parallel with the active filter.

The two algorithms have been digitally implemented on the DSP and utilized to process the voltage at the Point of Common Coupling (PCC), in order to test their capability to track the supply voltage in all the typical operating conditions of an aircraft power system. The digital implementation of both algorithms has been performed at sampling frequency equal to $8 \mathrm{kHz}$. The execution time of the DFT-PLL was equal to $30 \mu \mathrm{s}$, while the SSLKF-PLL algorithm takes about $2 \mu$ s. The conditions in which the tests have been performed were selected on the basis of the document RTCA DO-160E [36], which defines a series of standard environmental test conditions and test procedures for airborne equipment.

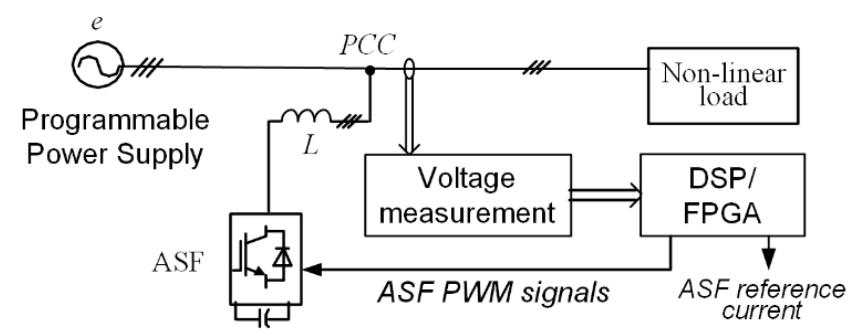

Fig. 5. Scheme of the experimental setup.

In order to obtain the results presented here, the parameters of the SSLKF-PLL algorithm and the ones of the DFT-PLL have been set in order to have similar dynamic responses with the two techniques. In particular, for the SSLKF-PLL, the parameter $R$ has been set to 10 , in order to obtain an underdamped response which presents the best compromise between transient response characteristics, overshoot and steady-state oscillations of the frequency step response. The value of the angle $\phi$ has been fixed to 45 degrees.

For the DFT-PLL algorithm, the observation window chosen for the real-time DFT of the signal is equal to one fundamental 
period at $400 \mathrm{~Hz}$, which corresponds to 20 samples of the signal, at $8 \mathrm{kHz}$ sampling frequency.

The two algorithms have been tuned in order to obtain the frequency estimation with similar speed of response for a frequency step from $400 \mathrm{~Hz}$ to $800 \mathrm{~Hz}$, on a balanced and sinusoidal three-phase voltage signal with amplitude equal to $115 \mathrm{~V}$ RMS phase-neutral, which is the typical supply voltage level in a More Electric Aircraft power system. This frequency step condition is not specifically indicated in [36]; however, it has been selected for parameters tuning because it represents the most critical case in the estimation of frequency and phase during a frequency transient. Furthermore, the frequency step occurs between values that characterize the variable frequency supply of the More Electric Aircraft. According to the latest research in the field, this range is comprised between $360 \mathrm{~Hz}$ and $900 \mathrm{~Hz}$. The tuning has been repeated for two values of closed-loop bandwidth: $10 \mathrm{~Hz}$ and $60 \mathrm{~Hz}$. For the SSLKF-PLL the closed-loop bandwidth is selected by changing the value of the parameter $\omega_{\mathrm{n}}$; for the DFT-PLL, appropriate values of the proportional and integral gain of the PI loop filter have been designed in order to yield the same speed of response as the SSLKF-PLL. For bandwidth equal to $10 \mathrm{~Hz}$, the PI gains have been fixed to 0.1 and 15 , for proportional and integral gain respectively. For bandwidth equal to $60 \mathrm{~Hz}$, their values have been set to 0.1 and 145 .

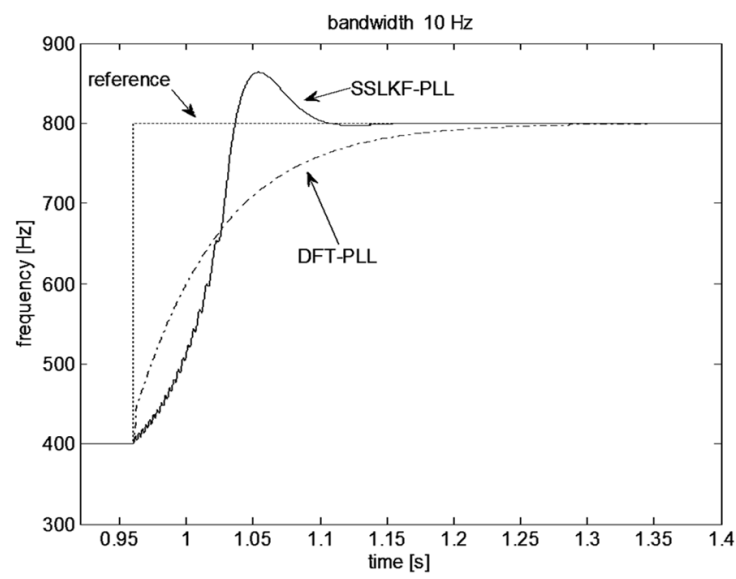

(a)

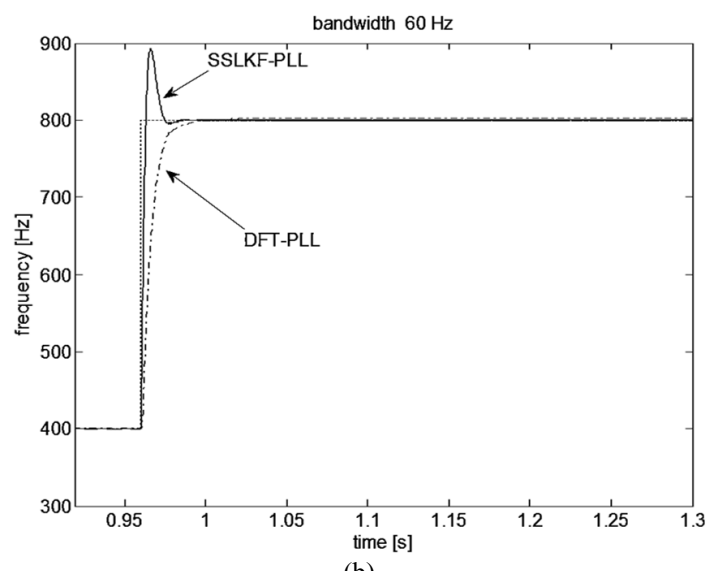

(b)

Fig. 6. Frequency estimation at frequency step from $400 \mathrm{~Hz}$ to $800 \mathrm{~Hz}$ : (a) bandwidth $10 \mathrm{~Hz}$; (b) bandwidth $60 \mathrm{~Hz}$.
The SSLKF-PLL provides a second-order under-damped response, while the DFT-PLL gives a first-order over-damped response. The frequency estimate provided by the two algorithms for the $400-800 \mathrm{~Hz}$ step is shown in Fig. 6 for both chosen bandwidth values. Table II summarizes the characteristics of the response obtained by the two methods.

Fig. 7 shows the estimate of the fundamental phase angle (in percentage error) provided by both algorithms at the occurrence of the frequency step. It can be seen that, after the step occurrence, the phase estimation error of the SSLKF-PLL decays more quickly than the DFT-PLL. The time taken for the error to decay to $20 \%$ for the $10 \mathrm{~Hz}$ bandwidth response is $0.127 \mathrm{~s}$ for the SSLKF-PLL and $0.2 \mathrm{~s}$ for the DFT-PLL. These two values are respectively $0.01 \mathrm{~s}$ and $0.025 \mathrm{~s}$ for the $60 \mathrm{~Hz}$ bandwidth response. The second test was run with frequency varying as a ramp from $360 \mathrm{~Hz}$ to $900 \mathrm{~Hz}$ with slope $100 \mathrm{~Hz} / \mathrm{s}$, which is indicated in the standards DO-160E as the slope of frequency during normal and abnormal conditions of operation.

Table II. Transient and steady-state performance of the frequency step estimation for a sinusoidal balanced signal.

\begin{tabular}{|c|c|c|c|c|}
\hline \multicolumn{5}{|c|}{ FREQUENCY STEP, SINUSOIDAL BALANCED SIGNAL } \\
\hline & \multicolumn{2}{|c|}{ 10Hz BANDWIDTH } & 60Hz BANDWIDTH \\
\hline & SSLKF & DFT & SSLKF & DFT \\
\hline $\begin{array}{c}\text { Maximum } \\
\text { overshoot [\%] }\end{array}$ & 16 & ----- & 23.22 & ------ \\
\hline Delay time [s] & 0.055 & 0.04 & 0.0014 & 0.0049 \\
\hline $\begin{array}{c}\text { Rise time [s] } \\
\text { [s] }\end{array}$ & 0.0546 & 0.1379 & 0.0022 & 0.0118 \\
\hline $\begin{array}{c}\text { Settling time 5\% } \\
\text { Peak time [s] }\end{array}$ & 0.1242 & 0.1853 & 0.012 & 0.0166 \\
\hline $\begin{array}{c}\text { Steady-state } \\
\text { oscillation max } \\
\text { amplitude [\% of } \\
\text { the steady-state } \\
\text { value] }\end{array}$ & 0.0125 & 0.0250 & 0.55 & 0.1 \\
\hline $\begin{array}{c}\text { Steady-state } \\
\text { error [Hz] }\end{array}$ & 0.0355 & 0.2261 & 0.0356 & 2.1927 \\
\hline
\end{tabular}

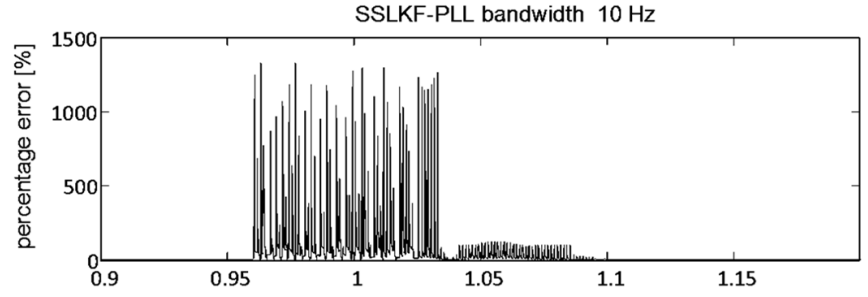

DFT-PLL

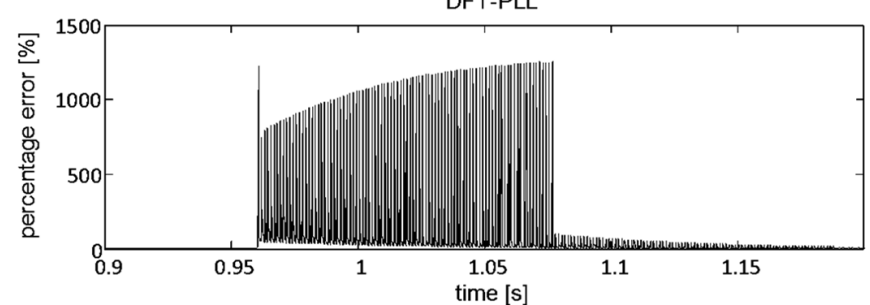

(a) 

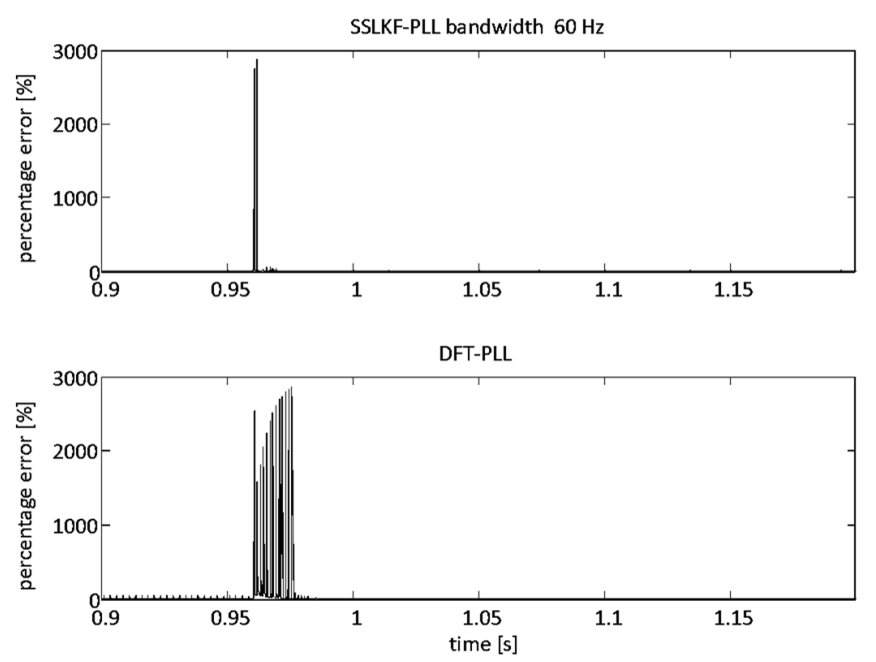

(b)

Fig. 7. Phase estimation at frequency step: (a) bandwidth $10 \mathrm{~Hz}$; (b) bandwidth $60 \mathrm{~Hz}$.

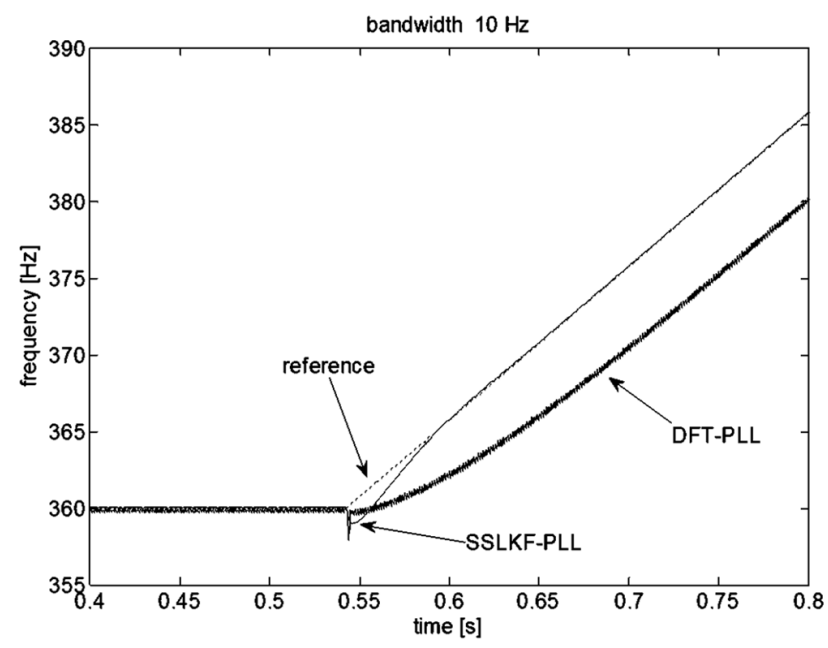

(a)

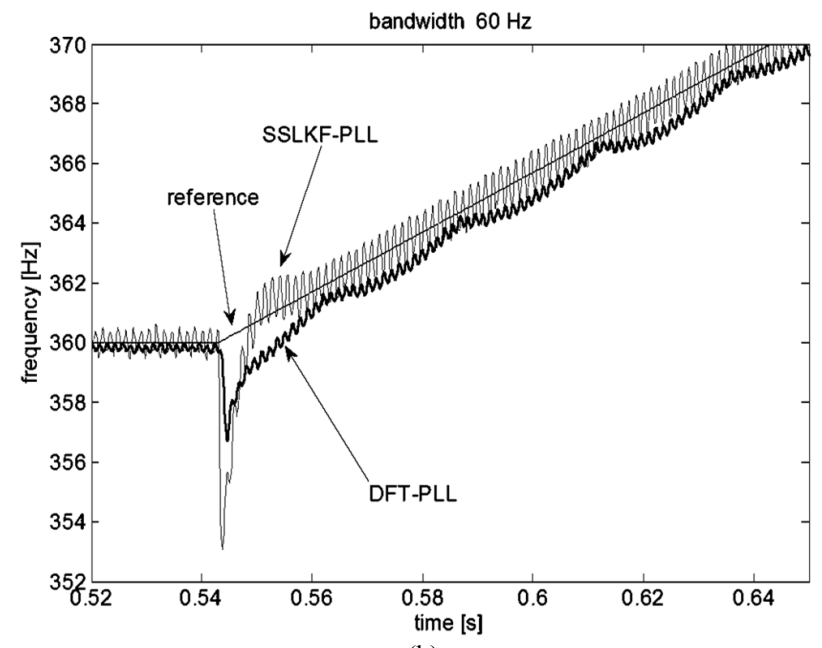

(b)

Fig. 8. Frequency estimation at frequency ramp with slope $100 \mathrm{~Hz} / \mathrm{s}$ : (a) bandwidth $10 \mathrm{~Hz}$; (b) bandwidth $60 \mathrm{~Hz}$.
Table III. Transient and steady-state performance of the frequency ramp estimation with slope $100 \mathrm{~Hz} / \mathrm{s}$.

\begin{tabular}{|c|c|c|c|c|}
\hline \multicolumn{5}{|c|}{ FREQUENCY RAMP WITH SLOPE 100Hz/s } \\
\hline & $\mathbf{1 0 H z}$ BANDWIDTH & \multicolumn{2}{|c|}{ 60Hz BANDWIDTH } \\
\hline & SSLKF & DFT & SSLKF & DFT \\
\hline Tracking time [s] & 0.052 & ---- & 0.005 & ------ \\
\hline $\begin{array}{c}\text { Steady-state } \\
\text { error [Hz] }\end{array}$ & 0.04 & 5.7 & 0.01 & 0.8 \\
\hline $\begin{array}{c}\text { Steady-state } \\
\text { oscillation max } \\
\text { amplitude [Hz] }\end{array}$ & 0.05 & 0.19 & 1.5 & 0.4 \\
\hline
\end{tabular}

Fig. 8 shows the responses of the two algorithms, particularly the initial portion of the ramp. In Table III the characteristics of both responses in this case are reported. From Fig. 8 it can be noticed that on a frequency ramp response, which represents the most significant operating situation for aerospace power generators, the SSLKF-PLL presents a negligible tracking delay and a steady-state tracking error close to zero. However, for a $60 \mathrm{~Hz}$ bandwidth, the steady-state oscillations amplitude is quite larger than the DFT one, even though such amplitude can be still considered acceptable, as it remains lower than $0.5 \%$ of the tracked frequency. In order to avoid the introduction of wider oscillations, which can negatively affect a controller using the proposed PLL, it is advisable to select a bandwidth value lower than $60 \mathrm{~Hz}$.

A further experimental test has been run accounting a distorted supply voltage, shown in Fig. 9a, generated by the AC power supply intentionally programmed to introduce harmonic components with individual amplitudes equal to $8 \%$ of the fundamental. This level of harmonic content corresponds to the maximum limit indicated in [36] for the AC supply voltage. A comparison between the harmonic contents is illustrated in Fig. 9b showing individual harmonics produced by the sine of grid angle $\tilde{\theta}$ estimated by the DFT-PLL (grey bar) and by the SSLKF-PLL (light grey bar); the harmonics values, expressed as a percentage of the fundamental at $400 \mathrm{~Hz}$, are also compared to the supply voltage ones (black bars). The harmonic analysis has been limited to the $9^{\text {th }}$ harmonics because, as previously mentioned, the sampling frequency has been set to $8 \mathrm{kHz}$. As it can be noticed from Fig. 9b, the SSLKF-PLL is able to significantly reduce the grid voltage harmonics, whilst the DFT-PLL produces an opposite result.

Figs. $10 \mathrm{a}$ and $10 \mathrm{~b}$ present the responses of the two algorithms, respectively obtained for a $10 \mathrm{~Hz}$ and a $60 \mathrm{~Hz}$ bandwidth, corresponding to a frequency step from $400 \mathrm{~Hz}$ to $800 \mathrm{~Hz}$, as well as an amplitude step of $20 \mathrm{~V}$, applied in $0.96 \mathrm{~s}$. 


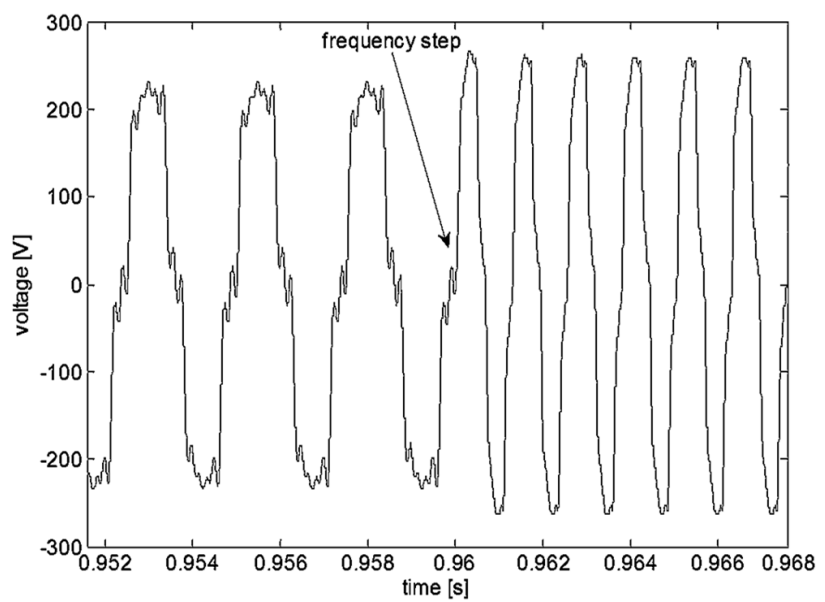

(a)

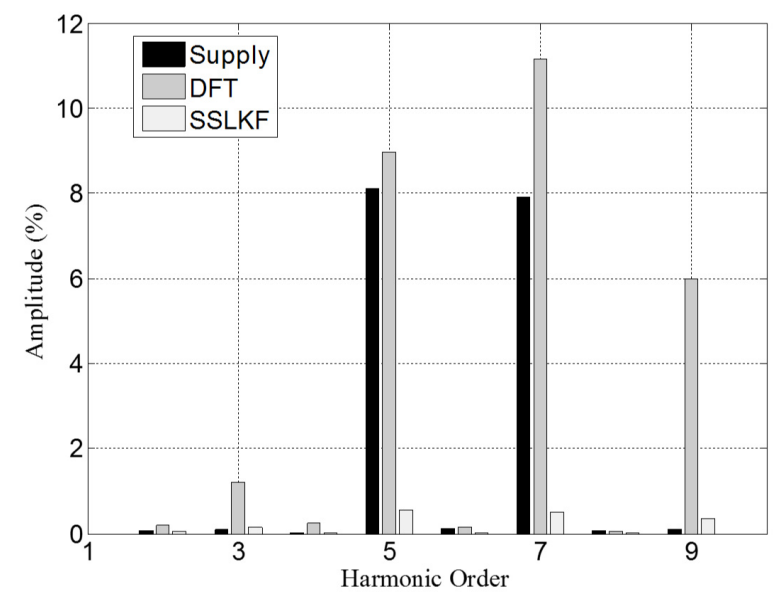

(b)

Fig. 9. (a) Distorted voltage with frequency step from $400 \mathrm{~Hz}$ to $800 \mathrm{~Hz}$. (b) Harmonic content comparison.

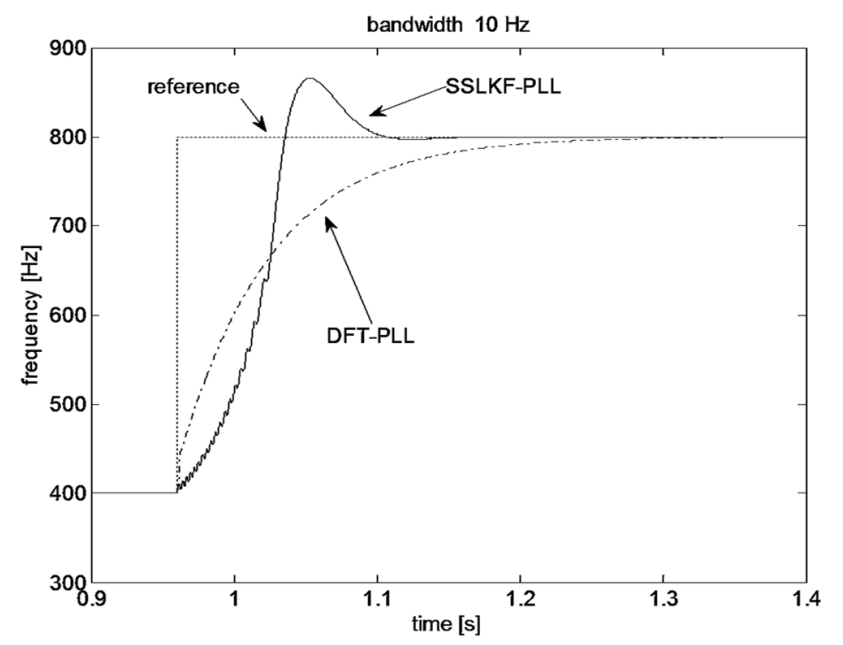

(a)

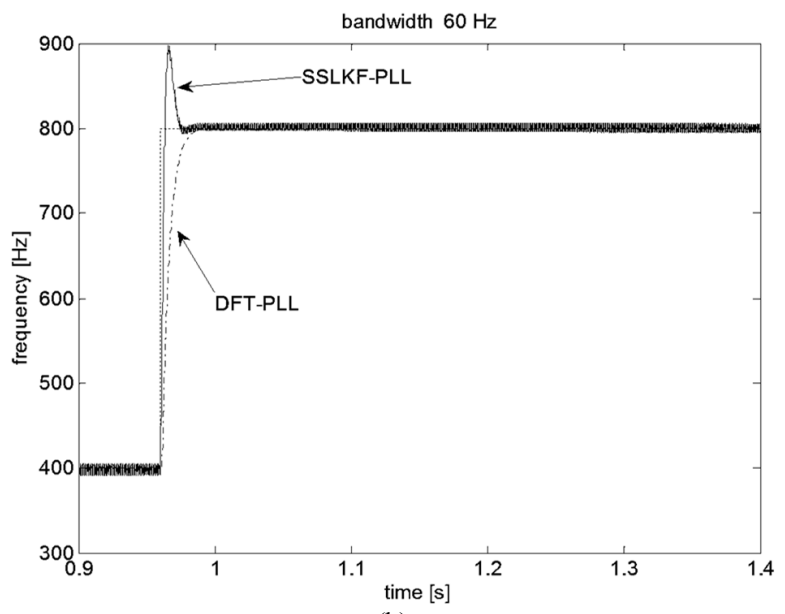

(b)

Fig. 10. Frequency estimation at frequency step from $400 \mathrm{~Hz}$ to $800 \mathrm{~Hz}$ for a distorted signal: (a) bandwidth $10 \mathrm{~Hz}$; (b) bandwidth $60 \mathrm{~Hz}$.

Table IV. Transient and steady-state performance of the frequency step estimation for a distorted balanced signal.

\begin{tabular}{|c|c|c|c|c|}
\hline \multicolumn{5}{|c|}{ FREQUENCY STEP, DISTORTED BALANCED SIGNAL } \\
\hline & \multicolumn{2}{|c|}{ 10Hz BANDWIDTH } & \multicolumn{2}{|c|}{ 60Hz BANDWIDTH } \\
\hline & SSLKF & DFT & SSLKF & DFT \\
\hline $\begin{array}{c}\text { Maximum } \\
\text { overshoot [\%] }\end{array}$ & 16.25 & ----- & 24.375 & ----- \\
\hline Delay time $[\mathrm{s}]$ & 0.0575 & 0.04 & 0.0015 & 0.0050 \\
\hline Rise time $[\mathrm{s}]$ & 0.0547 & 0.1379 & 0.0021 & 0.0117 \\
\hline $\begin{array}{c}\text { Settling time } \\
5 \%[\mathrm{~s}]\end{array}$ & 0.1237 & 0.1851 & 0.012 & 0.017 \\
\hline Peak time $[\mathrm{s}]$ & 0.093 & ----- & 0.006 & ----- \\
\hline $\begin{array}{c}\text { Steady-state } \\
\text { oscillation max } \\
\text { amplitude [\% } \\
\text { of the steady- } \\
\text { state value] }\end{array}$ & 0.0794 & 0.0272 & 3.3540 & 0.0494 \\
\hline $\begin{array}{c}\text { Steady-state } \\
\text { error }[\mathrm{Hz}]\end{array}$ & 0.0375 & 0.0378 & 0.0325 & 0.2036 \\
\hline
\end{tabular}

In Table IV the characteristics of both responses are listed in detail. Also in this case the raise and the settling time of the SSLKF-PLL are shorter than the DFT ones, even if the steadystate oscillations are wider for a $60 \mathrm{~Hz}$ bandwidth.

Figs. 11 and 12 show the results of a test carried out on an unbalance three-phase voltage. The unbalance level, 10V RMS difference between the phase with the highest voltage and the phase with the lowest voltage, corresponds to the maximum limit indicated in [36] for emergency operation. Fig. 11 shows the experimental voltage and Fig. 12 shows the frequency estimation provided by the two algorithms in the two cases, $10 \mathrm{~Hz}$ and $60 \mathrm{~Hz}$ bandwidth. In Table $\mathrm{V}$ the characteristics of the responses for this test are listed. 


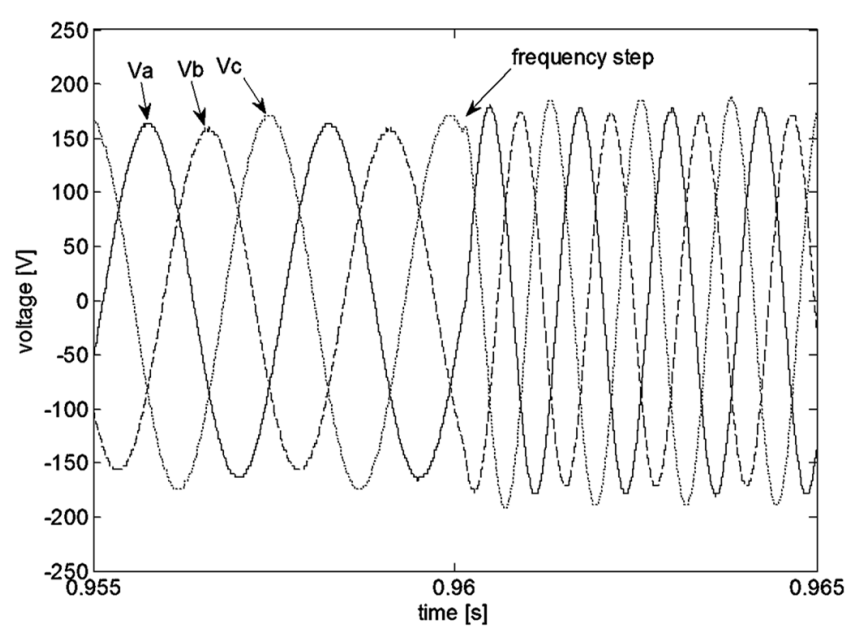

Fig. 11. Unbalanced voltages with frequency step from $400 \mathrm{~Hz}$ to $800 \mathrm{~Hz}$.

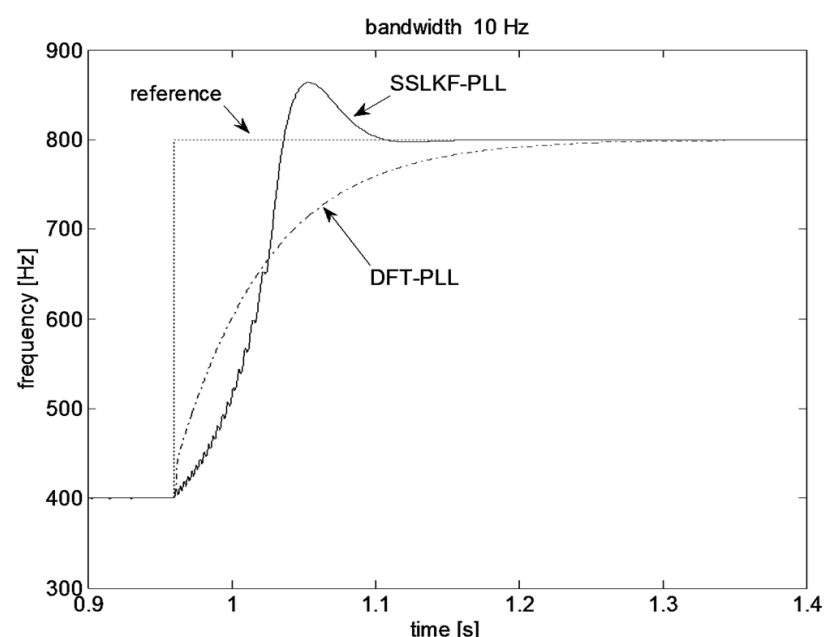

(a)

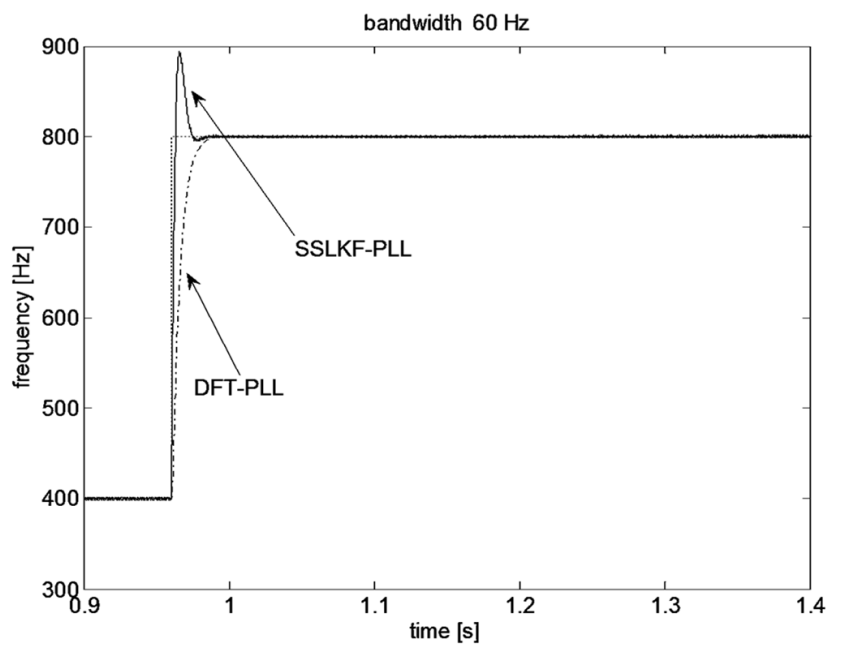

(b)

Fig. 12. Frequency estimation at frequency step from $400 \mathrm{~Hz}$ to $800 \mathrm{~Hz}$ for an unbalanced signal: (a) bandwidth $10 \mathrm{~Hz}$; (b) bandwidth $60 \mathrm{~Hz}$.
Table V. Transient and steady-state performance of the frequency step estimation for a sinusoidal unbalanced signal.

\begin{tabular}{|c|c|c|c|c|}
\hline \multicolumn{5}{|c|}{ FREQUENCY STEP, SINUSOIDAL UNBALANCED SIGNAL } \\
\hline & \multicolumn{2}{|c|}{ 10Hz BANDWIDTH } & \multicolumn{2}{|c|}{ 60Hz BANDWIDTH } \\
\hline & SSLKF & DFT & SSLKF & DFT \\
\hline $\begin{array}{c}\text { Maximum } \\
\text { overshoot [\%] }\end{array}$ & 16 & ----- & 23.5 & ----- \\
\hline Delay time $[\mathrm{s}]$ & 0.0574 & 0.04 & 0.0015 & 0.005 \\
\hline Rise time $[\mathrm{s}]$ & 0.055 & 0.139 & 0.0021 & 0.0117 \\
\hline $\begin{array}{c}\text { Settling time } 5 \% \\
{[\mathrm{~s}]}\end{array}$ & 0.1241 & 0.185 & 0.0118 & 0.0171 \\
\hline Peak time $[\mathrm{s}]$ & 0.094 & ----- & 0.006 & ----- \\
\hline $\begin{array}{c}\text { Steady-state } \\
\text { oscillation max } \\
\text { amplitude [\% of } \\
\text { the steady-state } \\
\text { value] }\end{array}$ & 0.0285 & 0.018 & 0.936 & 0.0297 \\
\hline $\begin{array}{c}\text { Steady-state } \\
\text { error }[\mathrm{Hz}]\end{array}$ & 0.0355 & 0.0351 & 0.0357 & 0.2176 \\
\hline
\end{tabular}

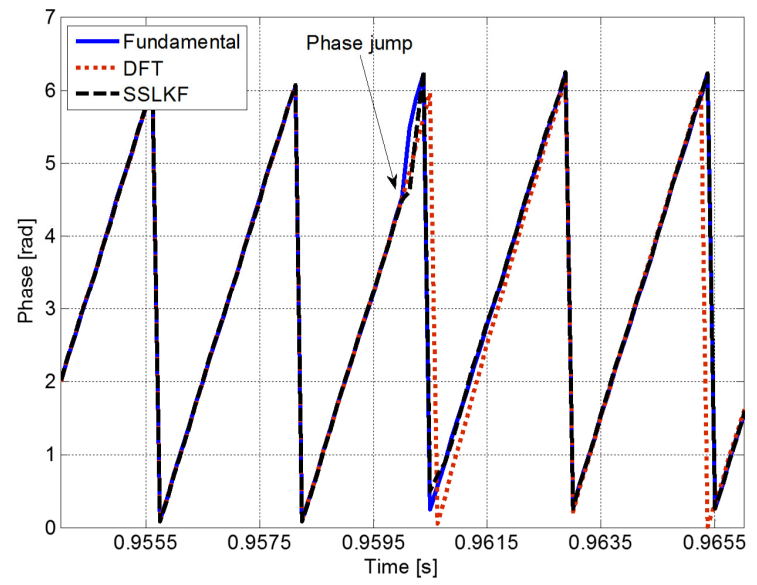

(a)

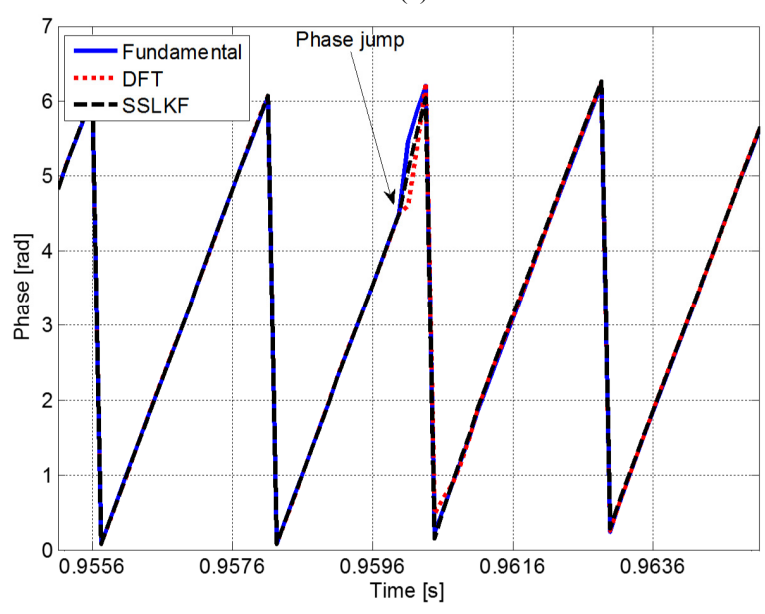

(b)

Fig. 13. Phase estimation at 50 degrees phase jump: (a) bandwidth $10 \mathrm{~Hz}$; (b) bandwidth $60 \mathrm{~Hz}$. 
Fig. 13 shows the comparison, for the two different bandwidths, of the phase estimation provided by the algorithms during the occurrence of a 50 degrees phase jump, considering clean supply voltages. It can be seen that, after the occurrence of the phase jump, the transient of the SSLKF-PLL is significantly shorter than the DFT-PLL for both bandwidths, but is particularly evident for $10 \mathrm{~Hz}$ bandwidth.

The presented results have highlighted that SSLKF-PLL method performs overall better both in steady-steady and transient responses and for either accounted bandwidths, despite of a slightly larger overshoot during transients. In particular, in the most significant test with a $100 \mathrm{~Hz} / \mathrm{s} \mathrm{ramp}$ variation of the supply frequency, the SSLKF-PLL provides the frequency estimation with a delay close to zero. This feature is particularly important because allows to increase the bandwidth of a closed-loop control system that employs the frequency estimation as feedback.

Performances of both methods are not significantly affected by harmonic distortions and unbalances on the supply voltage. Moreover, SSLKF-PLL presents a significantly lower computational complexity than DFT-PLL even if this latter can provide an estimation of the supply voltage harmonics.

\section{CONCLUSIONS}

The paper presents the application of a software PhaseLocked Loop, based on a prediction-correction third-order discrete filter (SSLKF-PLL), providing the estimation of phase and frequency of an aircraft power system supply voltage. Such task is particularly challenging in More Electric Aircraft power supply whose frequency is linearly variable in the range $360-900 \mathrm{~Hz}$ according to standards DO-160E.

A practical procedure that permits an easy tuning of filter parameters has been presented as well as an approximate formula to determine the bandwidth. The SSLKF-PLL has been experimentally compared with an estimation technique specifically designed for aircraft power systems, which adopts a real-time DFT technique as the PLL phase detector. The comparison has been performed from experimental results, obtained by a real-time DSP implementation, for two different bandwidths and various operating conditions of the supply voltage, including harmonic distortions and unbalances.

The results have highlighted that SSLKF-PLL technique provides superior performances than DFT-based in almost all cases and in particular provides the frequency estimation with a delay close to zero on a ramp variation of the supply frequency. This feature is particularly important because allows to increase the bandwidth of a closed-loop control system which employs the frequency estimation as a feedback. In addition, SSLKF-PLL algorithm requires, on a DSP running at $250 \mathrm{MHz}$, an execution time equal to $2 \mu \mathrm{s}$ which is a significantly lower computational effort than that of DFT-PLL, equal to $30 \mu \mathrm{s}$; however, DFT-PLL can provide also an estimation of the supply voltage harmonics which is required in case of active shunt power filter use.

\section{REFERENCES}

[1] I. Moir and A. Seabridge, Aircraft Systems: Mechanical, Electrical and Avionics Subsystem Integration. London, U.K.: Professional Engineering, 2001.

[2] A. Emadi and M. Ehsani, "Aircraft power systems: Technology, state of the art and future trends," IEEE Aerosp. Electron. Syst. Mag., vol. 15, no. 1, pp. 28-32, Jan. 2000.

[3] J. A. Rosero, J. A. Ortega, E. Aldabas, and L. Romeral, "Moving towards a more electric aircraft," IEEE Aerosp. Electron. Syst. Mag., vol. 22, no. 3, pp. 3-9, Mar. 2007.

[4] M. Padmanabhan and K. Martin, "Resonator-based filter-banks for frequency-domain applications," IEEE Trans. Circuits Syst., vol. 38, no. 10, pp. 1145-1159, Oct. 1991.

[5] M. Dölen and R. D. Lorenz, "An industrially useful means for decomposition and differentiation of harmonic components of periodic waveforms," in Conf. Rec. IEEE IAS Annu. Meeting, 2000, pp. 1016-1023.

[6] G. Simon, R. Pintelon, L. Sujbert, and J. Schoukens, "An efficient nonlinear least square multisine fitting algorithm," IEEE Trans. Instrum. Meas., vol. 51, no. 4, pp. 750-755, Aug. 2002.

[7] B. Chattopadhyay, C. Ivanov, and M. S. Sachdev, "A new frequency measurement algorithm in the presence of harmonics using instantaneous phasor quantities," in Proc. Can. Conf. Elect. Comput. Eng., 1996,pp. 130-133.

[8] P. K. Dash, A. K. Pradhan, and G. Panda, "Frequency estimation of distorted power system signals using extended complex Kalman filter," IEEE Trans. Power Del., vol. 14, no. 3, pp. 761-766, Jul. 1999.

[9] J. Barros and E. Pérez, "An adaptive method for determining the reference compensating current in single-phase shunt active power filters," IEEE Trans. Power Del., vol. 18, no. 4, pp. 1578-1580, Oct. 2003.

[10] F. Cupertino, M. Marinelli, and L. Salvatore, "EKF and waveletbased algorithms applied to harmonic detection for active shunt filters," in Proc. 11th Int. Conf. Harmonics Quality Power, 2004, pp. 721-727.

[11] G.-C. Hsieh and J. C. Hung, "Phase-locked loop techniques-A survey," IEEE Trans. Ind. Electron., vol. 43, no. 6, pp. 609-615, Dec. 1996.

[12] R. M. Santos Filho, P. F. Seixas, P. C. Cortizo, L. A. B. Torres, and A. F. Souza, "Comparison of three single-phase PLL algorithms for UPS applications," IEEE Trans. Ind. Electron., vol. 55, no. 8, pp. 2923-2932, Aug. 2008.

[13] H. Karimi, M. Karimi-Ghartemani, and M. R. Iravani, "Estimation of frequency and its rate of change for applications in power systems," IEEE Trans. Power Del., vol. 19, no. 2, pp. 472-480, Apr. 2004.

[14] V. Kaura and V. Blasko: Operation of a phase locked loop system under distorted utility conditions, IEEE Trans. Ind. Appl., vol. 33, no. 1, pp. 58-63, Jan./Feb. 1997.

[15] L. N. Arruda, S. M. Silva and B. J. C. Filho, "PLL structure for utility connected systems," Conf. Rec. 36th IEEE-IAS Annual. Meeting, vol. 4, pp. 2655-2660, 2001.

[16] C. Zhan, C. Fitzer, V. K. Ramachandaramurthy, A. Arulampalam, M. Barnes and N. Jenkins, "Software phase-locked loop applied to dynamic voltage restore (DVR)," Proc.of IEEE Power Eng. Soc. Winter Meeting, vol. 3, pp. 1033-1038, 2001.

[17] S. Chung, "A phase tracking system for three phase utility interface inverters," IEEE Trans. on Power Electron., vol. 15, no. 3, pp. 431438, May 2000.

[18] G. H. Jung, G. C. Cho and G. H. Cho "Improved Control for High Power Static Var Compensator Using Novel Vector Product Phase Locked Loop (VP-PLL)," Intern. Journal of Electronics, vol. 86, no.7, pp. 837-855, 1999.

[19] L.G. Barbosa Rolim, D. Rodrigues da Costa, Jr. and M. Aredes, "Analysis and Software Implementation of a Robust Synchronizing PLL Circuit Based on the pq Theory," IEEE Trans. Ind. Electron., vol. 53, no. 6, pp. 1919-1926, Dec. 2006. 
[20] D. Jovcic, "Phase Locked Loop System for FACTS, ” IEEE Trans. on Power Systems, vol. 18, no. 3, pp. 1116.1124, 2003.

[21] M. Karimi-Ghartemani, S.A. Khajehoddin, P.K. Jain and A.Bakhshai, "Problems of Startup and Phase Jumps in PLL Systems," IEEE Trans. Power Electron., vol.27, no.4, pp.18301838, April 2012.

[22] A.V. Timbus, M. Liserre, R. Teodorescu and F. Blaabjerg, "Synchronization methods for three phase distributed power generation systems. An overview and evaluation," Proc. of PESC'05, pp. 2474-2481, 2005.

[23] P. Rodriguez, J. Pou, J. Bergas, J. I. Candela, R. P. Burgos, D Boroyevich: Decoupled double synchronous reference frame PLL for power converters control, IEEE Trans. Power Electron., vol. 22, no.2, pp. 584-592, 2007.

[24] A.V. Timbus, R. Teodorescu, F. Blaabjerg, M. Liserre and P. Rodriguez, "PLL Algorithm for Power Generation Systems Robust to Grid Voltage Faults," Proc. of $37^{\text {th }}$ IEEE Power Electronics Specialists Conference, PESC '06, pp. 1 - 7, June 2006.

[25] M.C. Benhabib and S. Saadate, "A new robust experimentally validated phase locked loop for power electronic control," $E P E$ Journal, vol. 15, n.3, pp. 36-48, 2005.

[26] Y. Han, L. Xu, M.M. Khan, G. Yao, Li-Dan Zhou and C. Chen, "A novel synchronization scheme for grid-connected converters by using adaptive linear optimal filter based PLL (ALOF-PLL)," Simulation Modelling Practice and Theory, vol. 17, Issue 7, pp. 1299-1345, August 2009.

[27] M. Karimi-Ghartemani and M.Reza Iravani, "A method for synchronization of power electronic converters in polluted and variable-frequency environments," IEEE Trans. Power Syst., vol. 19, n.3, pp. 1263-1270, 2004.

[28] F.D. Freijedo, A.G.Yepes, O. López, A.Vidal and J. Doval-Gandoy, "Three-Phase PLLs With Fast Postfault Retracking and SteadyState Rejection of Voltage Unbalance and Harmonics by Means of Lead Compensation," IEEE Trans. Power Electron., vol.26, no.1, pp.85-97, Jan. 2011.

[29] Y. F. Wang and Y. Wei Li, "Analysis and Digital Implementation of Cascaded Delayed-Signal-Cancellation PLL," IEEE Trans. Power Electron., vol.26, no.4, pp.1067-1080, April 2011.

[30] Y. F. Wang and Y. Wei Li, "Grid Synchronization PLL Based on Cascaded Delayed Signal Cancellation," IEEE Trans. Power Electron., vol.26, no.7, pp.1987-1997, July 2011.

[31] P. Rodríguez, A. Luna, R. Muñoz-Aguilar, I. Etxeberria-Otadui, R. Teodorescu and F. Blaabjerg, "A Stationary Reference Frame Grid Synchronization System for Three-Phase Grid-Connected Power Converters Under Adverse Grid Conditions," IEEE Trans. Power Electron., vol.27, no.1, pp.99-112, Jan. 2012.

[32] A. Bellini and S. Bifaretti, "A Digital Filter for Speed Noise Reduction in Drives using an Electromagnetic Resolver," Mathematics and Computers in Simulation, vol. 71, issues 4-6, pp. 476-486, June 2006.

[33] A. Bellini and S. Bifaretti, "Performances of a PLL Based Digital Filter for double-conversion UPS," Proc of $13^{\text {th }}$ Int. Conf. on Power Electronics and Motion Control Conference, EPE-PEMC 2008 , Poznan (Poland), September, 2008.

[34] A. Bellini, S. Bifaretti and V. Iacovone, "Robust PLL Algorithm for Three-Phase Grid-Connected Converters," EPE Journal, Vol. 20 no. 4, December 2010.

[35] F. Cupertino, E. Lavopa, P. Zanchetta, M. Sumner, and L. Salvatore, "Running DFT-Based PLL Algorithm for Frequency, Phase, and Amplitude Tracking in Aircraft Electrical Systems," IEEE Trans. on Ind. Electron., vol. 58, no.3, pp.1027-1035, March 2011.

[36] DO-160E, Environmental Conditions and Test Procedures for Airborne Equipment, RTCA, 2004. 